\title{
Response to Commentators on Suffering and Virtue
}

\author{
Michael Brady ${ }^{1}$
}

Accepted: 14 September 2021 / Published online: 13 October 2021

(c) The Author(s) 2021

It has been an honour and a pleasure to read and engage with three commentaries from four of the best philosophers working on virtue. I have learnt a great deal from reading these, and talking about the issues at the APA symposium on the book in April 2021. Some of the things I have learnt concern mistakes I made in the book: in its content, or argumentation, or tone. These might be sins of commission. Some concern areas it would have been profitable to talk about some more, and so reflect sins of omission. Some of the things I have learnt are different ways of defending my views, or further avenues for profitable investigation. Perhaps most of all, I have been reminded, once more, about the virtues displayed when smart and talented and conscientious and generous people give their time and effort to critically evaluate the work of others, and to push philosophical thinking forward. Perhaps that is the most important thing to learn from symposia like these, and one of the very great values of academia: how fulfilling and satisfying such collaborative efforts to talk, to understand, and to pursue the truth can be. I am very grateful indeed to all of my commentators, to Alycia LaGuardia-LoBianco, who chaired the APA session; and especially Iskra Fileva, who organised the session - not once, but twice, due to the pandemic - and whose sterling work has resulted in this publication.

\section{Response to Christian Miller}

I would like to thank Christian Miller for his very kind words, his careful and fascinating commentary, and also for being one of the readers for OUP of the original manuscript. His comments there helped the book to be considerably better than it would have been, and for this too I owe him a great deal of thanks.

Christian raises some important issues about my account of suffering, the idea that suffering is a motive for faculty virtues, the relation between suffering and the view of wisdom I adopt in the final chapter, and finally the intriguing issue about whether parallel claims concerning enjoyment and vice are plausible. I take these in

Michael Brady

michael.brady@glasgow.ac.uk

1 University of Glasgow, Glasgow, UK 
turn, and hope that I can do Christian's thoughts and comments justice. I find myself in agreement with much of what he has to say.

\subsection{The Desire View of Suffering}

Suffering (final account): A subject suffers when and only when she has (i) an unpleasant experience consisting of a sensation $\mathrm{S}$ and a desire that $\mathrm{S}$ not be occurring, and (ii) an occurrent desire that this unpleasant experience not be occurring (55).

(i) Christian notes, quite rightly, that it is possible to want one's suffering to end, and so on my account this means that "I want that it not occur that I want that it not occur that my want that this sensation not be occurring". He asks whether this follows from my account, and if so whether it is unduly cumbersome, complex, and perhaps even psychologically unrealistic. Now it is apparent, from Christian's comments and also from those of Nancy, Heather, and Amy, and that I need to do more to explain and defend the desire-accounts, of unpleasantness and of suffering. I am happy to attempt this here!

The first thing to note is that the correct account of suffering will in all likelihood diverge from what we think and say about suffering, at least pre-philosophically. (This is no surprise. It is highly likely that the correct account of knowledge will diverge from what we think and say about knowledge, at least pre-philosophically - not least because notions of warranted justified belief that meets the Gettier conditions are not entertained by people who say that they know London lies south of Manchester.) It is clearly true that when we want our suffering to stop, we have nothing like the above content explicitly in mind. If my account is psychologically unrealistic, then it's not psychologically unrealistic in this sense.

The second thing to note is that the actual sentence might strike one as unduly cumbersome and complex in part because it suggests that we have all of these desires that are themselves directed at desires, rather than - as I think I want to say - at experiences. So: when I want to stop suffering, I want my experience of suffering to cease. As it turns out, then, the object of my want is an experience, and this consists of a relation between a desire and an unpleasant experience. When I desire that the unpleasant experience cease, this is directed at another experience, viz. one where I desire that some sensation cease. So: I want to stop suffering = I want to stop experiencing an unpleasant state that I mind. And this doesn't seem too problematic. A final response is to say that in the end, complexity might well be the price I have to pay for an account that goes beyond what I take to be genuine problems for internalist accounts, and an account which holds that suffering is more than mere unpleasantness.

(ii) Christian raises another problem, that of Tiny Unpleasantness. His example is The Small Itch: "I have the smallest of itches on my leg. I barely notice it, but I do, and I give it a quick scratch." He thinks I must say that I am suffering before the scratch, and that this seems implausible. I agree that this might seem problematic. However, if it is true (as it seems to be) that the itch is unpleasant, and so consists of a desire that the itch sensation stop, might it not be this desire that does 
the motivating, rather than any additional desire directed at the unpleasantness? Perhaps noticing the itch doesn't make the experience one in which I suffer; instead, it might function to 'trigger' the desire in question. We can, I take it, be motivated to do things like scratch an itch because we desire that the sensation stop, rather than insisting that we desire that the unpleasant experience stop.

(iii) Christian raises the excellent point about the bearing of the theoretical accounts in Chapters 1 and 2 on the rest of the book, and whether (as he suspects) anything in the later chapters would be significantly different if other accounts of suffering and unpleasantness were adopted (e.g. internalist ones). If so, it might then look as though the chapters are otiose! I share his worry here. I have two brief responses. First, it would look odd in a book on suffering if I didn't give some account of what suffering is, or some account of perhaps the core element in suffering, namely unpleasantness. Second, we might think that one important question is what suffering is, and a second is what suffering does. It might well be that the former, though worth answering, ends up having little to do with answering the latter. Consider a similar concern in metaethics. There are very great debates in metaethics as to the nature of moral judgements - between expressivists, error theorists, cognitivists, to name but three. But all seem to agree on basic claims about what moral judgements do: they motivate, are used to express disagreement, are used to persuade others, are used to express one's deepest moral values, maintain social norms, etc. Perhaps the slight strangeness of doing considerable theoretical work on the nature of suffering, which then has little to do with suffering's value, is a phenomenon of this type. It's just that in the case of suffering, very few people have done either.

\subsection{Suffering as a virtuous Motive}

Christian also raises very good questions about my take on faculty virtues, where I seem to adopt a consequentialist approach as to whether something constitutes a virtue - in terms of whether it reliably brings about valuable ends. He asks (i) whether this raises concerns, given my adoption of a more Aristotelian account of trait virtues, and (ii) whether the Aristotelian would have legitimate complaints about a consequentialist account to assessing faculties.

In response, I think that a pluralistic approach to the nature of virtues is warranted, and so we ought to accommodate both Aristotelian and consequentialist elements when thinking about virtue. At least, I think that this is warranted if we want to maintain that feelings constitute the motivational components of virtue. This is because there is a good case for pluralism about the nature of feelings or emotions. On my view, there is no one theoretical approach that best captures the nature of emotions. Some emotions are much closer to instinctive bodily reactions (disgust; surprise; terror). Others are much closer to evaluative judgements (contempt; schadenfreude). Some others are closer to perceptual judgements (jealousy; anger). Because of this, some virtues that have feelings as motivational components will be closer to bodily responses (pain), while others will be closer to intellectual judgements (schadenfreude). So that's the first thing in support of some form of pluralism. 
The second thing to say is that my account of faculty virtues need not be (and I think is not) purely consequentialist, since the feelings that partly constitute faculty virtues - such as feelings of pain - can themselves be appropriate or fitting to their situation. Thus pain is fitting or appropriate if it is a response to bodily damage, as well as reliably motivating appropriate pain behaviour. Now of course, Aristotelians might respond to both of these by trying to limit the class of feelings that can constitute the motivational components of virtue. But other than an insistence on doing so because this fits in with Aristotelian theory, I don't see for myself a principled reason for such a restriction.

Christian also raises the interesting question of potential conflict between faculty and trait virtues - as when a faculty virtue leading to avoidance or repair behaviour conflicts with a trait virtue that doesn't seek to eliminate the suffering. Which, he asks, should get the upper hand? He thinks it is tempting to say that it's the trait virtue. Now I would imagine that this could be defended on Nietzschean grounds - where we are implored to seek out occasions for suffering, in order to overcome it. Nietzsche clearly thinks that trait virtues associated with strength, fortitude, and patience have priority over things like pain - although he never talks of the latter as virtuous. Perhaps, however, there are cases where faculty virtues have priority over trait virtues - at least, if we think that the avoidance of pain and physical hardship in those suffering from debilitating illness, for instance, can justify or warrant one's being less-than-fully compassionate on occasions - and if Lisa Tessman is right, on many occasions if one is subject to oppression. (This is a point that Amy and Heather raise later on.)

\subsection{Suffering and Wisdom}

I found Christian's thoughts here fascinating and find myself very much in agreement with the overall line he is pushing. I am happy to call myself a practical wisdom eliminativist, therefore! I can then appeal to distinct traits or set of dispositions to correspond to the relevant functions. There is an interesting question as to how these particular dispositions are linked if they are distinct. It seems to me that there are connections between the capacities here: compassion would seem to be necessary for being inclined to give good advice; deliberative and reflective thinking is likely to be enhanced insofar as one is intellectually humble; extensive experience is surely a factor in coming to understand oneself and the world; and so on. But I am very willing to agree with Christian that there is reason to reject appeal to one virtue, wisdom, that is meant to do all of the work here.

\subsection{What About Vice?}

In the final section of his comments, Christian raises really fascinating questions about vice, and the lack of focus on vice in the book. In particular, he raises the question of whether there are interesting connections between the opposites of suffering and virtue, viz. enjoyment and vice. First, I think I might prefer 'joy' to 'enjoyment', insofar as it suggests greater intensity. If a terrible life is one filled with suffering, 
a wonderful life might be one filled with joy. (That sounds better than a life filled with enjoyment - somehow that doesn't sound good enough!) Secondly, I think an account of joy in terms of pleasantness we want to continue (either because it is very intense, or because it has great meaning) is likewise plausible, at least initially.

Do I want to claim that joy is necessary for injustice? Whilst I agree that taking joy in unfairness or discrimination makes those things even worse, it's not clear that joy is necessary for injustice. The suffering necessary for justice seems to do with feelings of remorse, which motivates reparations, apologies, etc. There doesn't seem the same link between joy and injustice - it's not as if those who commit unjust acts need to take pleasure in them, although sometimes they do. I agree that the other inverted claims are no more plausible. So now the puzzle is, as Christian puts it, to explain why necessary conditions hold in one case, but not in the other. How might we solve this puzzle? One tentative answer lies in the motivational story I want to tell. Suffering is needed when we face the problem of doing what is good for us: avoiding and repairing bodily damage, reflecting on our wrongdoing and making reparations, avoiding danger when this requires exertion, etc. Here the negative feelings involved in pain and suffering have a vital motivational role, since mere evaluative belief or judgement won't do the job, or won't do the job nearly as well. However, we don't need any particular positive motivation towards vice in many cases - to ignore the claims of others (callousness, injustice), or to give in to fear (cowardice). These motivational forces stem in the main from our selfish and self-interested nature, which is amply provided for motivationally. So I think that the difference in motivational stories might well be the way to solve the puzzle - although this is very much a tentative response to a deep and very interesting question.

\section{Response to Nancy Snow}

I am very grateful to Nancy for her detailed, fascinating, and generous comments. They have motivated me to think a good deal about some of the issue in the book, and realise areas where I could have said more, and other areas where I could have said things better. It would have been a different book as well if I'd be writing it now, post covid. Nancy's own positive suggestions are very welcome and I'll look forward to thinking much more about them. Nancy's main focus is on Chapters Four and Five, and I'll take these in turn.

\subsection{Two Themes from Chapter Four, 'Suffering and the Virtues of Strength and Vulnerability'}

Nancy focuses on my claim that suffering is necessary for us to develop and express virtues that constitute strength of character. She raises a very interesting and important question that arises if we distinguish meaningful from meaningless suffering, and asks 'whether meaningless suffering is necessary for developing strength of character.' Nancy rightly points out that meaningless suffering might undermine (or perhaps - has a greater tendency to undermine) character strength. Perhaps then it is 
only suffering that the sufferer regards as meaningful which is necessary for developing virtues of strength. She illustrates this with nice examples: where pain and mental suffering are inflicted with the precise aim of breaking people down, where emotional abuse is arbitrary and has the same aim. Such things not only intend to destroy character, but will typically do so. Nancy thinks that 'unless the sufferer experiences what she is going through as meaningful, I think it is highly likely that she will not develop virtues of strength, but instead will end up either sinking into apathy or developing attitudes of despair, hostility, and resentment toward her plight.'

In response, I am happy to accept that meaningless suffering might well be more likely to undermine strength, especially when it is intentionally imposed or inflicted. The meaningless of suffering would plausibly make it easier to despair. However: (i) the point about timing is important here. In many cases of post-traumatic growth, suffering that is experienced as meaningless at the time can come to be seen as meaningful after a period of growth, as a result (e.g.) of a subject's re-evaluating her circumstances. In this case, she develops strength despite suffering that is, at the time, perceived as meaningless. (ii) It might well be the case, as John Hick suggests, that it is undeserved, unmerited, suffering that allows the most morally valuable response. Perhaps the greatest strength requires meaningless suffering, which might well then constitute a greater moral achievement. (And moral achievement is a central element of meaning in life.) This seems true even though I accept Nancy's sensitive accounts of the meaningless of much suffering associated with COVID, diseases where knowledge is incomplete, and so on. Here too I agree with her point that in many cases, lots of conditions have to be in place in order for someone to develop virtues of strength in the face of suffering - such as reliable information and knowledge about the disease. Again, it's not that suffering by itself is sufficient, but that it is arguably necessary.

Nancy also raises important issues about praise and blame, and here I am very much in agreement with what she says. I certainly think that praising those who develop strength as a result of adversity can too easily lead into 'bright-siding', and blaming those who do not develop virtues of strength (or any other virtue) can in many cases be highly inappropriate. It must be especially galling to be blamed by those who are not in the same circumstances and not suffering in the same way. This isn't just a moral point, against adding misery to one who is suffering greatly. It's also false to criticise the sufferer, according to the lights of my account, since as I point out, some negative responses to suffering - for instance, resentment and anger at (e.g.) injustice, or illness - are cases in which a person responds entirely appropriately to these things. Moreover, since so many other conditions need to be in place in order for one to respond well, apportioning blame as if developing virtue was completely in the agent's own gift is often likewise mistaken. So I entirely agree with Nancy's claim that we wouldn't be justified in blaming someone who doesn't develop strength in the face of adversity, nor think them vicious, for there are many reasons why strength can't be cultivated. As Nancy says, however, deliberately choosing some negative attitudes, when other options are possible, is one case where we're inclined to assign blame and detect vice. I'm thinking of someone who wallows in his grief or guilt, or who engages with this in a self-indulgent manner, or 
who turns heartless and cruel instead of compassionate. But other negative attitudes, as noted, seem perfectly appropriate. In short, I agree with Nancy's overall take on the relations between suffering, praise, and blame here.

\subsection{Virtues of Vulnerability}

Nancy notes the interesting possibility of psychological tension between sufferers who strive to be strong, and yet who develop and cultivate virtues of vulnerability. 'These two sets of virtues seem to pull their possessor in opposite directions in terms of character development.' Nancy's example is of someone striving to be resilient, and yet humble about her ability to overcome hardship. This is an interesting possibility, although I think that the kind of humility characteristic of those who are ill (for instance) is humility about their achievements, or career, etc., a kind of humility which seems fully compatible with resilience. The relevant limitations here concern my previous goals in many cases: I now know, given my illness, that I'll never be the great footballer or musician that I strived to be. Likewise, fortitude doesn't seem in tension with other virtues of vulnerability, such as compassion for others, or creative adaptation to illness. There might well be other problematic cases here though, as Nancy suggests, where strength requires a kind of confidence and even the kind of self-aggrandizement that is the opposite of humility. To cope with and be courageous in the face of my illness, perhaps I have to think that I can be great (again). This raises the interesting question of non-standard virtues - or even things that might appear to be vices - that are needed in order for someone to be resilient, cope, creatively adapt. (This is familiar from Tessman's work, and illustrated nicely in Havi Carel's book Illness, where she talks about the need to 'toughen up' and become rude in the face of cruel comments from strangers. That is a vital coping mechanisms in the face of her illness.) I very much like Nancy's idea of a better way though - of hope as cognitive resolve. So there are different ways that illness and humility are related, and I thank Nancy for pointing out one such dimension. Her conclusion in this section is that "perhaps the virtues that should be prescribed depend very specifically on the circumstances and moral psychology of sufferers. Virtues of strength could be appropriate for some people, virtues of vulnerability for others.' This fits in very nicely with my point about virtues being relativized to different parts of one's life, in many cases.

\subsection{Reflections and Themes from Chapter Five, 'Suffering, Morality, and Wisdom'}

Nancy makes a number of very good points here - with which I entirely agree - highlighting the fact that the kind of self-reflection needed for meaning-making is not always possible to those who are suffering, and that even when it is, it might not make the suffering meaningful. Instead, reflection might only make suffering intelligible. And as she points out, intelligibility and meaningfulness are different things, and intelligibility is a first step on the road to meaning. Likewise, Nancy raises here the point I suggested earlier about time and its importance to seeing meaning. As she states, 'time can give us a vantage point from which to reflect on and manage the 
negativity of the experience', though again the sense of being 'safe from a distance' might be much more difficult in some cases than others. Again, I entirely agree that 'so much depends on the psychology of the sufferer and her circumstances', a point I should have made more of in the book.

Nancy's final point highlights the importance of community in the narrative one constructs, and the centrality of hope to this. 'I think that what is needed to make our experiences of suffering meaningful is hope.' I certainly think that this is true of some forms of suffering; and optimism is one of the markers for and contributors to post-traumatic growth. Since meaning can be constituted by many kinds of moral achievement, in addition to understanding, it will be interesting to see if hope is central to virtues of strength and vulnerability as well - something I very much want to think about in later work.

\section{Response to Amy Coplan and Heather Battaly}

I am very grateful to Amy and Heather for raising a number of really important points, and concerns about Suffering and Virtue. They have made me reflect and think deeply about a lot of the book, and the range and subtlety of the comments is very impressive. Amy and Heather focus on five themes: (i) the desire account of suffering; (ii) the role of suffering in virtue-development; (iii) whether suffering is required for evaluative knowledge; (iv) heroism and selflessness, and (v) the reduction of suffering. I won't have time to do them justice in what follows, but I hope to say something about each. I do think that we are closer and in substantial agreement on very many points here - perhaps more than might initially appear.

\subsection{The Desire Account of Suffering}

Amy and Heather raise a number of worries about my account of suffering.

(i) Doesn't it imply that garden-variety masochists, 'who seek out and revel in pain, don't find pain unpleasant', on the grounds that they don't want the pain to stop? They think that this is the wrong result, if we think the sensation of pain is itself unpleasant, and that masochists have a second-order desire for pain because it is unpleasant. So unpleasantness seems like an intrinsic property of some sensations, like pain. In response, I might simply point out that garden-variety masochists do want the pain to stop - this follows from a desire-account of unpleasantness - but don't necessarily want the painful experience to stop. Masochists seek out and revel in painfulness, not pain.

(ii) Repentant criminals. On my account, repentant criminals suffer. Doesn't the above suggest that they don't, since they don't want the unpleasant experience to stop? They want, instead, the unpleasant experience to continue, because they think it deserved. This is a good point, but again is one that I can accommodate. For I might ask a different question in turn: Is the unpleasant experience of remorse one that the repentant criminal minds having? If not, it is difficult to think that it would be serious enough an experience to be what they deserve. It's like saying: 'I know 
that being imprisoned and feeling guilty is unpleasant, but to be honest I don't really mind these feelings.' That doesn't seem to capture what the repentant criminal wants. They want unpleasant experience that is minded, that they do mind, because it is only this kind of state that they regard as serious enough to be a reflection of their repentance. They desire that the unpleasantness cease, in other words, but at a higher level welcome the situation in which this more serious negative affective state occurs. Without the additional desire, we have no way of distinguishing merely unpleasant experiences of remorse, and ones that are 'seriously' unpleasant. It is the latter that seems to be a mark of genuine repentance.

(iii) For Amy and Heather, virtuous persons won't suffer either. According to them, conscientious people, when feeling remorse, have unpleasant experiences (consisting of a sensation that they desire cease - note that this need not be an occurrent desire), but do not 'want not to have the unpleasant experience itself', since what they want 'is to be the kind of people who have unpleasant experiences when they have acted wrongly. (It should be noted that here they shift from talking of my account of unpleasantness as consisting of a sensation plus a desire that it cease, to talking of a sensations that we are bothered by, and so perhaps smuggling in my occurrent desire. I suspect that the initial plausibility of the objection is due to this move.) Amy and Heather write: 'conscientious people want to feel remorse and be bothered by it - they want the unpleasant experience - they don't want to feel remorse but be indifferent to it.' So they don't have a second-order desire not to have the unpleasant experience, 'and even have a second-order desire to have the unpleasant experience when they have acted wrongly.'

My response here mirrors the above: conscientious people want to suffer from remorse, not just have unpleasant feelings of remorse. For again, the latter might be mild, so much so that the remorseful person isn't bothered by them. On my account, it is possible to have unpleasant experiences that one is not bothered by - and this must be as true of experiences of remorse as any other experiences. What the conscientious person wants isn't just to have unpleasant remorse experiences, in other words. I think (as with Christian's comments) part of the worry here stems from thinking of the desire that is operative in unpleasantness as an occurrent desire - the kind of thing we have when we desire to visit a Greek island on holiday, let's say. But it's not like that. It is something that is attributable to us in virtue of the fact that we find something unpleasant, on the theoretical grounds that only positing a desire here can best capture what painfulness and unpleasantness is. It's not the kind of thing that that is readily apparent to us when we consciously reflect- otherwise, why would anyone disagree with the desire theory? I think that the complications here are often stemming from the fact that I didn't get clear enough about the nature of this desire, and especially what it isn't.

\subsection{The Role of Suffering in Virtue-Development}

Amy and Heather argue that suffering is not necessary for the development of virtue, and that the best type of character education involves no suffering. For Aristotle, correct education is a matter of training pleasures and pains appropriately. 
Importantly, 'education' involving the 'correct formation of our feelings of pleasure and pain, which makes us hate what we ought to hate from first to last, and love what we ought to love', will be 'carried out through recreation, playtimes, and games. Poetry, construed broadly to include singing, dancing, acting, etc., and physical education will be the primary activities through which children's souls are imbued with preferences for what is good and aversion to what is bad.' They write that such education prescribes a path to virtue that contains no suffering, although it might well involve feelings of discomfort and unpleasantness and struggles. But this suggests, to my ears at least, either that the correct education involves unpleasantness and discomfort that the children never mind - unpleasantness that is never intense, struggles that they never desire to cease - in which case it seems highly unrealistic. Or perhaps it's the case Aristotle means something different from suffering than I do. Are we to imagine that children do not suffer when they see other children being bullied, or in poverty, or when they view animal cruelty? Are we to imagine that children are not to grieve should a parent die, and that being educated into the correct response towards death is, although unpleasant, not one of suffering? I guess I remain unconvinced that properly educated children will not suffer in these instances, but no doubt because I know far too little about Aristotle's account of education.

Amy and Heather's next point concerns the role of suffering in developing courage, and cases where people actively pursue activities because they involve suffering and challenges. Amy and Heather are puzzled by this. They worry that if such agents are ultimately motivated by pursuit of their own strength and social standing, then this might well undermine the development of virtuous (intrinsic) motives, because extrinsic motivation and reward undermines intrinsic motivation. I agree with them here, if the aim of enhancing strength and social standing were the conscious aim or goal of these activities. However, I don't think that such things are usually conscious aims when people pursue things that will enhance their social standing. Instead, they are a condition on the value of pursuing other things that are consciously aimed at. To see this, note that doing arduous or difficult things is a condition on achieving things - as Gwen Bradford plausibly claims in her book Achievement. Being motivated to achieve something is, I take it, an intrinsically virtuous motive, at least if we think that achievement is an objective good, something that people pursue for its own sake. So it isn't obvious that such motivations are non-virtuous.

Amy and Heather also worry that motivations to improve might be problematic, because such agents might as a result do little to make others stronger. This is fair enough. But nothing I say in the book implies that improving oneself is one's only motivation. I might add: why think that pursuit of difficult things (like working out, or doing philosophy) only benefits oneself? Working out in order to become fit would seem to have all kinds of instrumental effects - in terms of one's mental health, one's capacity to work, lessening of demand on the health service, and so on. Achievement is surely compatible with virtuous motives to help others. So I think that if we bring achievement into the picture, egoistic worries recede somewhat - unless we think that our pursuit of any achievements are problematically egoistic. Finally: I don't think that these are the only ways in which one can develop courage of course, because we face many other challenges than ones we intentionally pursue. 
The point is the psychological one that we do pursue things that are difficult, that this is a way of developing and cultivating strength, that this can be valuable - for ourselves and others.

\subsection{Is Suffering Required for Evaluative Knowledge?}

Amy and Heather wonder why suffering - rather than other motives, such as curiosity and a desire to know - is a motivation for epistemic goods. 'Why can't a desire to know, e.g., whether my behaviour is implicitly racist, motivate my reflection instead of suffering?' Positive desires and motivations - to make myself a morally better person, to feel good about trying to improve myself - might do this. Now I think that these are all very good points, and perhaps then I should restrict my claim about the epistemic value of negative affect to a restricted range of epistemic goods: knowledge about and understanding of negative values. Certainly negative emotion is often very important for moral improvement - a point which is at the heart of the story of Guatama Buddha - and so negative emotion is often at the heart of compassionate engagement with others, which is a common motive for self-improvement. At the same time, I think that curiosity is a strangely ambivalent emotion: one feels excited about getting the truth, but also frustrated by the fact that one doesn't. I think it's the latter which is a common motivating factor in curiosity.

\subsection{Heroism and Selflessness}

Amy and Heather also have concerns about some of the implications of my views in Chapter 6. The first is about the view that suffering (in initiation rites) is essential to expressions of faith in and commitment to one's community. They worry that this 'positive account of suffering risks valorizing an unhealthy ideal of the sort often associated with notions of the heroic and hypermasculinity'. They question whether the sort of value this practice has for the Gisu should be classed as beneficial and associated with virtue, and is a dangerous example to use as a paradigmatic case. For one thing, they worry that the initiation rite is akin to torture. For another, the ritual has longlasting implications for those who pass, and those who do not. Valorizing a willingness to ensure pain and suffering and remain undaunted is, as Susan Bordo has argued, problematic, insofar as it perpetuates an ideal that is dangerous and unrealistic, with those who are unable or unwilling to undergo excruciating pain considered unworthy. This is an unhealthy machismo ideal. Now I certainly don't want to valorize torture, nor unhealthy machismo ideals. But nor do I suggest that suffering excruciating pain is the highest form of courage and commitment, though it is clearly a form of courage and commitment. In the case of initiation rites, I suspect that some will be of considerable benefit to a community or group, others less so. Cases of the latter may indeed be more common; think of obvious examples of the cruel and bullying and occasionally fatal hazing that goes on in fraternity houses. Still, we can compare this with the more positive team-building initiations, where new members of sports teams have to perform a song or routine, or low-level hazing that occurs on one's first day at work, and where the ability to take part in, show willing, and submit oneself to this without complaint might well be important for one to be accepted into a group. (It's important 
to know that new players and colleagues are sufficiently humble, and are not narcissistic enough, to do this.) So clearly the justification of such practices will vary widely.

Amy and Heather also question the value of suffering for loving relationships, and in particular the necessity of selfless suffering. Here as elsewhere, I suspect that I have overplayed my hand somewhat, and some qualifications might have been in order. So I think that what Amy and Heather say here is plausible. Nevertheless, the stronger claims I make on this issue still to my mind have a deal of plausibility. Amy and Heather suggest that deep loving relationships need not require us to place another's well-being above our own, or to subordinate this. I think that this is true, but it depends upon what subordination means. I deny that a particular and extreme form of selflessness is a requirement for loving relationships; but a willingness to be selfless at times for the sake of another is surely constitutive for love. This is compatible with thinking that the well-being of oneself and one's partner are equally important, and so there is no priority given to well-being across a relationship or across time. But one had better be willing to be selfless on occasion, for love to exist, and indeed for love to be deep. This is true for all those involved in relationships, and so I'm not sure that anything I say may lead to or help to justify unjust systems of oppression, in which certain groups but not others are expected to prove their love and commitment through repeated acts of selflessness. I don't promote, nor do I write about, people sacrificing or giving up 'everything' for the sake of others - e.g. mothers for the sake of their children. Indeed, I explicitly talk about people sacrificing 'some of their needs and comforts', and I would hope that it is understood that this is true for both people in loving relationships. I hope, then, that I don't give the impression that I am in any way 'glorifying a brand of selflessness'.

\subsection{Reducing Suffering}

I agree with Amy and Heather on this final point, at least to the extent that those suffering oppression might have little opportunity to develop and express virtues, and that doing so with virtues like compassion can itself detract from a person's flourishing. Still, I don't agree that even in these circumstances - the kind horribly illustrated by covid - suffering lacks virtue-theoretic value. It might well lack the kind of instrumental value discussed above. But feeling pain in such circumstances is nevertheless an appropriate and fitting response to the situation, and so counts as a faculty virtue in this instance, albeit one that is, when we think what is all-things-considered valuable, outweighed by the considerable negative value of the suffering. So less suffering is indeed required for the development and cultivation of many of the virtues outlined in the final chapters, although even here - as solidarity, community, neighbourliness, and group action have shown - significant social virtues are still possible, and often extremely valuable.

I would like to close by again saying how much I appreciate the care, consideration, and time that has gone into producing the three excellent commentaries, and hope that my responses go some way to doing them justice. 
Open Access This article is licensed under a Creative Commons Attribution 4.0 International License, which permits use, sharing, adaptation, distribution and reproduction in any medium or format, as long as you give appropriate credit to the original author(s) and the source, provide a link to the Creative Commons licence, and indicate if changes were made. The images or other third party material in this article are included in the article's Creative Commons licence, unless indicated otherwise in a credit line to the material. If material is not included in the article's Creative Commons licence and your intended use is not permitted by statutory regulation or exceeds the permitted use, you will need to obtain permission directly from the copyright holder. To view a copy of this licence, visit http://creativecommons.org/licen ses/by/4.0/.

Publisher's Note Springer Nature remains neutral with regard to jurisdictional claims in published maps and institutional affiliations. 